\title{
A Novel Groundwater Resource Forecasting Technique for Cultivation Utilizing Wireless Sensor Network (WSN) and Machine Learning (ML) Model
}

\author{
K. Padmanaban ${ }^{\text {a }}$, K. S. Kannan ${ }^{\text {, }}$, D. Palanivel Rajan ${ }^{c}$, and P. Divya ${ }^{d}$ \\ Department of Computer Science and Engineering, Koneru Lakshmaiah Education \\ Foundation, Vaddeswaram, AP,India.. \\ bepartment of Computer Science and Engineering, CMR Engineering College, Hyderabad, Telangana India. \\ 'Department of Computer Science and Engineering, CMR Engineering College, \\ Hyderabad, Telangana India. \\ ${ }^{\mathrm{d} D e p a r t m e n t}$ of Computer Science and Engineering, Bannari Amman Institute of Technology, Sathyamangalam, Tamil nadu. \\ India.
}

Article History: Received: 11 January 2021; Accepted: 27 February 2021; Published online: 5 April 2021

\begin{abstract}
Groundwater is almost essential part of cultivation process, particularly in parched regions. The prophecy of groundwater intensity is crucial for understanding groundwater availability and provide systematic assistance for the cultivator that the stable convention of groundwater resource. A proposed efficient technique (ET) of forecasting the groundwater level (WFC) methodology was recognized in this study to precisely forecast groundwater intensity for cultivation in the parched regions of south India. Pumping facility, recharge capability of bore wells, exposure of cultivation area and weather conditions are used as key parameters, whereas groundwater level was considered as an output factor. The lack of systematic assistance about the groundwater availability also causes a decrease in the farmer's emotional stability and thereby affects their plan of enlightening the right crops and craft financial hardship. The proposed technique can be a new method for forecasting groundwater resource. The analytical and prediction reports of the proposed method will assist the farmers about the accessibility of groundwater resource and lead them to plan the cultivation of right crops and prevent from economic defeat.
\end{abstract}

Keywords: groundwater resource, forecasting Technique, Wireless Sensor Network, prediction of groundwater availability, Machine Learning.

\section{Introduction}

In India, agriculture consumes a maximum share of the groundwater. Irrigation plays a significant part in the cultivation process. Many of the agriculture regions of India are in drought due to lack of water resources. Borewell is an effective solution for those suffered regions. Using the effective method like vertical Electrical sounding, suitable water regions are found by the geologists. Wireless sensor networks (WSN) for agriculture has proved that to be supportive for irrigation and effective utilization of water. WSN is an infrastructure-less network deployed a huge number of sensors that reliably interact with physical or environmental conditions and deliver real-time data that is used in cultivation zones. WSNs are used to measure the environmental circumstances like humidity, temperature, soil moisture, etc. and organizing the sensed information at a central point. Climatic circumstances, over abuse of water, and nonexistence of optimum utilization of existing resources leads in a growing crisis of water. Groundwater is the highest significant resources of water source. However, in recent years, groundwater has been whittled down due to inadequate withdrawal and misapplication, increasing water scarcity in the future. [1]. Recently, investigators have used various scientific models to forecast groundwater levels. These models were designed to meet the difficulties of forecasting groundwater levels based on the collection of input and operational factors, a number of tunings and performance [2]. Further recent researches in the earlier few centuries were used soft-computation methods for forecasting groundwater levels [3]. The statistical model used to calculate distinctions level of groundwater in various environments of climate. The model is recognized from historical records of water stages nearly 80 wells in screening system. [4]. Considered various water sediment circumstances to expect water level by integrating classification and regression models $[5]$.

Groundwater is a very essential need of human's daily life especially in the field of cultivation. Nowadays, Groundwater resource monitoring and prediction is a challenging job for all developing countries. Groundwater resource is decreasing tremendously day to day. The prediction of groundwater is very much needed for domestic, industry and agriculture-related activities. Based on the prediction reports, people plan their water dependable applications effectively. The prediction accurateness plays a most important role in the organization of waterbased applications. There is a need of model to forecast forthcoming groundwater resource accessibility based on the present available information.

\section{Related Works}

The various methods and techniques help to the farmers for cultivating more crops and diminish pampering of water with sensor and modernization in irrigation scheme. This depends on cultivation zone data for soilmoisture sensors. The analysis can also be extended by considering method of light-intensity measurement in 
greenhouses and by making it easier for farmers to monitor condition of environment anywhere. [6]. Utilized a single panel system with in-built WiFi facility and connection established to a solar panel for providing essential operational power and the system considered the data from the sensors humidity, soil moisture, and temperature and produce a suitable command instruction to function the pumps for irrigation and as well as monitors the groundwater level to avoid from burning the pump motors [7].Presented smart system based Open-source technology for predict irrigation necessities area by identifying environment parameters such as soil temperature, soil moisture in consort with the online climate forecast information [8].Automated irrigation scheme has been functional for effective convention of water in an agriculture crops growth. The soil temperature and soil moisture sensors were used along with the wireless sensor networks (WSNs) facilitates to collect data and normalize it by stimulating actuators [9] [10].

Determine the properties of hydraulic features like bulk-density, operating pressure and soil-water content for two categories of SDI (Subsurface drip irrigation) and identified that operational pressure dominates the feature of flow rate for subsurface drip irrigation [11]. Discussed the water constraints and soil conditions for an agriculture field and how effectively supply the water using solar energy without human interaction and describing an effective scheme of irrigation to reduce the water consumption [12] [13]. Proposed an experimental model that relates groundwater level and climatic parameters. The model is demon started with a dataset containing past histories of water-levels about 80 and above wells in the network. The predicted results of ground water level variations in retort to various climate circumstances [14]. Explored several irrigation methods like vertical, soilless farming, and aquaponics implemented in water susceptible regions. The main objective is to reduce water resource convention and cost of formation in irrigation method.[15]. IoT is a united network of selfconfiguring ability sensors over predefined communication protocols wherever physical parameters of the realtime accurate result and control [16]. Two types of neural networks, Recurrent Neural Network and Multilayer Perceptron are used for building a prediction model in water level cascaded channels with high accurateness [17].Mining technologies were used in the farming to afford good suggestions to cultivators about crops price, crops revolution, seeds quality and identifiable attestations of required fertilizer [18] and assist the farmers can desire a suitable crop for their cultivation land [19]. Supervised and Un-supervised models of machine learning procedure be located in the field of cultivation [20]. Developed a system for monitoring agricultural process with wireless sensor networks. The sensed information has been communicated to the data server via wireless network [21].

\section{Problem Description}

The existing traditional methods of agriculture have more drawbacks specifically manual process of monitoring the cultivation zone, high expensive and nonexistence of efficient assistance system about the accessibility of ground water. Smart irrigation schemes are used to afford the solution for choosing right crops and the effective use of water. Ecological conditions are detected using sensors and the sensed data is shared by various applications to yield the decision on each time climate variations occurred in an agriculture atmosphere. However, groundwater resource prediction and monitoring are a challenging task. To overcome the problems of existing methods, the proposed technique is executed in the field of cultivation to predict the accessibility of groundwater resource for future and assist the farmers to plan right crops based on the accessibility of groundwater source and avoid financial defeat. The core contribution of proposed technique are as follows:

- Provides information about the ecological conditions based on sensor data.

- $\quad$ Protect extreme usage of water and electrical energy.

- Forecast the future availability of groundwater resource.

\section{Proposed Method}

\subsection{Architecture}

Wireless sensor network (WSN) refers as collection of isolated sensors deployed for monitoring the conditions of an environment and organizing the sensed data at a central location.Fig.1 shows the architecture of proposed (ET-WFC) methodology, the sensors are installed in the borewells in the selected parched region to determine the groundwater resource. These sensors are generally equipped with processing, sensing and transmitting capabilities and also responsible for measuring the parameters related to the particular function.

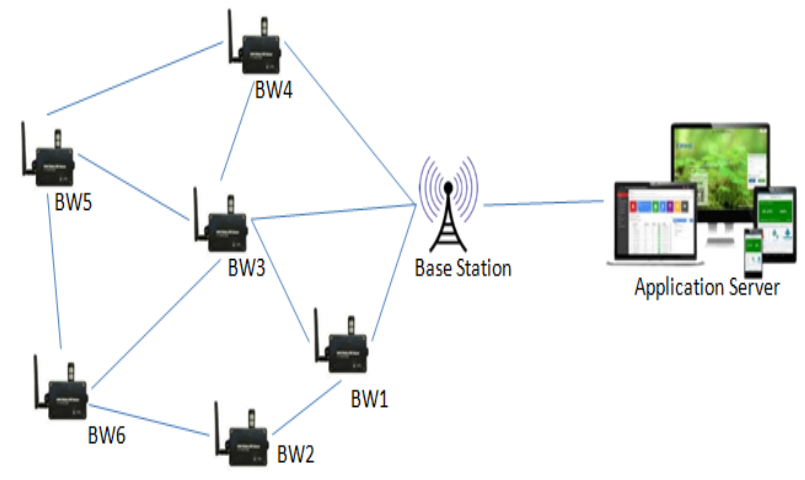


Fig.1: Architecture of proposed water resource forecasting technique (ET-WFC)

The base station is responsible for collecting sensed data from sensor nodes and forwarded it to application server. The application server receives the sensed data from the base station and process using a machine learning model to predict the availability of groundwater resource for the future.

4.2. Algorithm and Working Principle

In Fig. 2 demonstrates the proposed ET-WFC water resource forecasting technique in which the sensors such as soil moisture sensor (FC-28), temperature sensor (LM-35), water flow measurement sensor (YF-S201) and water level detection sensor (SEN-18) are linked with arduino micro controller. The sensed data are transmitted via integrated Wi-Fi module (ESP8266).

The ET-WFC technique appraises the received data based on the threshold metric value, then generates a positive signal by setting $G_{\text {LED }}$ with high value to turn on the electric pump motor for irrigation. Otherwise generates negative signal by setting $\mathrm{R}_{\mathrm{LED}}$ with high value to turn off the electric pump motor in order to save electricity and groundwater. Once the $\mathrm{G}_{\mathrm{LED}}$ register set to high, the water flow and water level monitoring sensors are activated then the groundwater level and flow of water are is measured. In case the water level or flow reached the threshold then the system generates a $\mathrm{R}_{\mathrm{LED}}$ signal and turns off the electric pump motor to save electricity and also prevent from burning electric pump motor due to heat caused when the water not in flow. Base-station connected with all sensors deployed in the field. It is responsible to collect the data from sensors and transmit to the application server.

The Application Server process the received real-time sensor data from the base station and prepares a data set for machine learning model. Machine Learning model incorporates a variety of statistical procedures and uses statistics (both past and present) to estimate or 'predict', future outcomes. The various analytical reports are obtained from an android app with modern user-friendly interface. Algorithm of the proposed water resource forecasting technique (ET-WFC) has been described in Table 1.

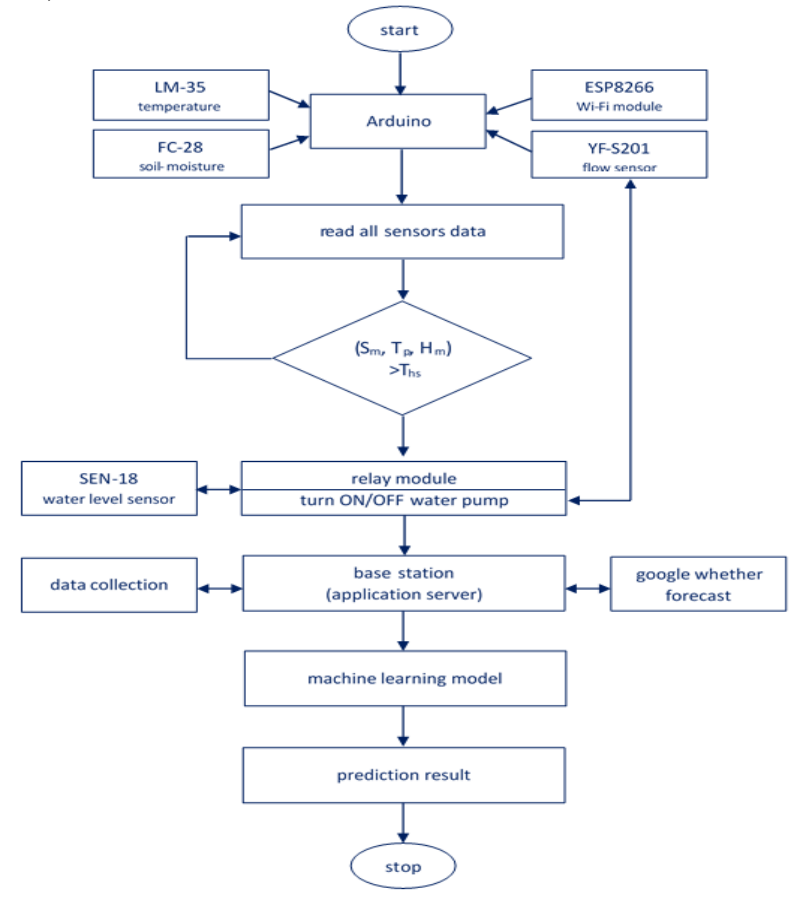

Fig. 2: Flow diagram of proposed water resource forecasting technique (ET-WFC)

\begin{tabular}{|c|}
\hline Algorithm: EF-WFC \\
\hline BEGIN \\
\hline READ $S_{m}, T_{p}, H_{m}$ \\
\hline $\begin{array}{c}\text { IF } S_{\mathrm{m}}>T_{\mathrm{hs}} \text { and Eval }\left(\mathrm{T}_{\mathrm{p}}, \mathrm{H}_{\mathrm{m}}\right) \text { THEN } \\
\operatorname{signal}\left(\mathrm{G}_{\mathrm{LED}}, \mathrm{High}, \mathrm{E}_{\mathrm{m}}\right)\end{array}$ \\
\hline
\end{tabular}

ELSE

$\operatorname{signal}\left(\mathrm{R}_{\mathrm{LED}}, \mathrm{High}, \mathrm{E}_{\mathrm{m}}\right)$

measure $\left(\mathrm{B}_{\mathrm{WL}}, \mathrm{C}_{\mathrm{lk}}\right)$

$\mathrm{P}_{\mathrm{W}}=\left|\mathrm{T}_{\mathrm{WL}}-\mathrm{B}_{\mathrm{WL}}\right|$

CALC $R_{c}$ of borewells 
UPDATE datasets

LOAD datasets into ML model

REDICT future outcomes

\subsection{Model}

The proposed technique for water resource forecasting (ET-WFC) builds a machine-learning model based on random forest algorithm. Both regression and classification problems are studied and resolved by using random forest. Random forest classifier consists a big amount of distinct decision trees. Each decision tree is spit out a prediction class and the class which has more polls turn into the prediction of a model. The proposed scheme uses the features of sensed data to build a model to make prediction of the accessibility of groundwater resource for cultivation.

\section{Performance Evaluation}

The performance of ET-WFC technique is analyzed by the installation of proposed technique in three borewells with an irrigation area of $150 \mathrm{ct}$. (ie., $\pm 65000 \mathrm{ft}^{2}$ ). All the three borewells are equipped with an equivalent pumping facility. Sensors are deployed for monitoring environment and sensed data are collected via wireless sensor networks from arduino micro controller to the base station. The performance of the ET-WFC technique is evaluated based on the parameters flow-rate, extraction-rate and recharge capability of borewells.

5.1. Water level

The water level in the borewells is measured as follows,

$$
\begin{aligned}
& w_{l}=\frac{3.14 \Delta P_{d} r^{4}}{8 L_{t}} \\
& P_{d}=\rho \times g_{r} \times h
\end{aligned}
$$

$w_{l}$ is the water level, $\Delta P_{d}$ is the pressure difference between top and bottom ends water levels, $r^{4}$ is the fourth power of borewell radius, and the length is $L_{t}$.

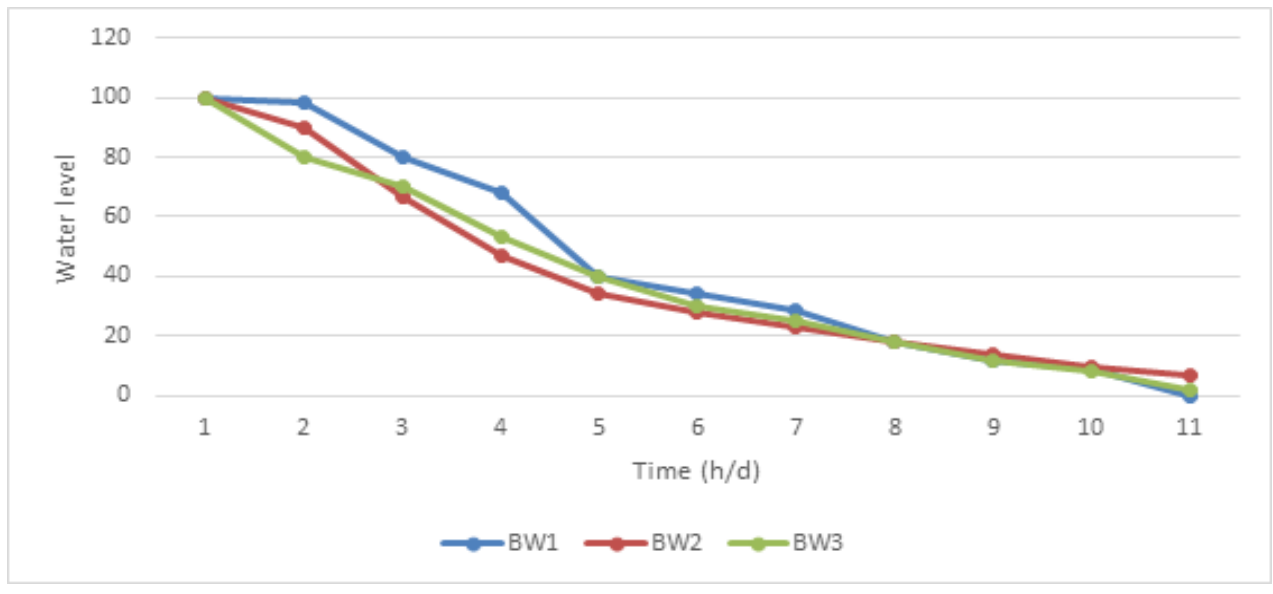

Fig. 3: Water level of borewells (ET-WFC)

Fig. 3. shows the percentage of groundwater accessibility in borewells based on the time period of the day using proposed ET-WFC technique.

\subsection{Extraction rate}

The extraction rate $E_{r}$ of water for irrigation and the electric pump setting $E_{p}$ is calculated as,

$$
\begin{aligned}
& E_{r}=\frac{\text { Total flow of water }(\mathrm{gal})}{\text { Area,sq.ft. }} \\
& E_{p}=\frac{\forall d f}{F_{\max }} \times 100 \%
\end{aligned}
$$




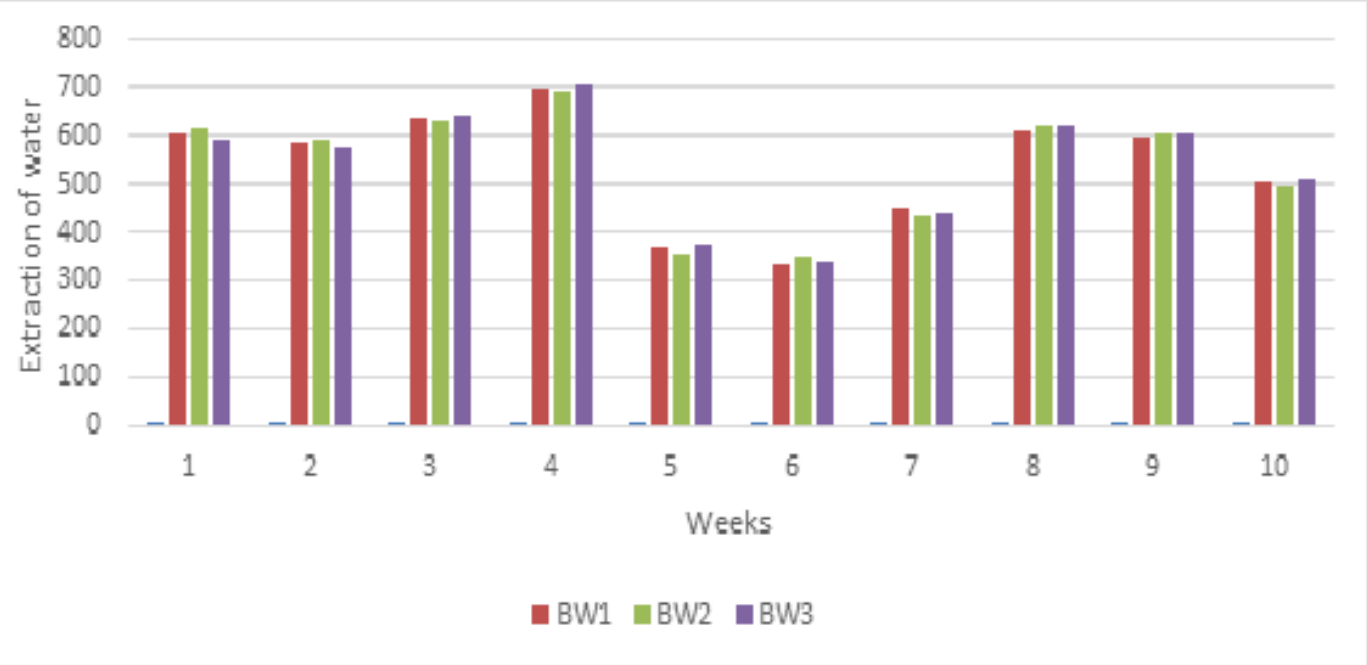

Fig. 4 (a):Extraction rate of water from borewells (ET-WFC)

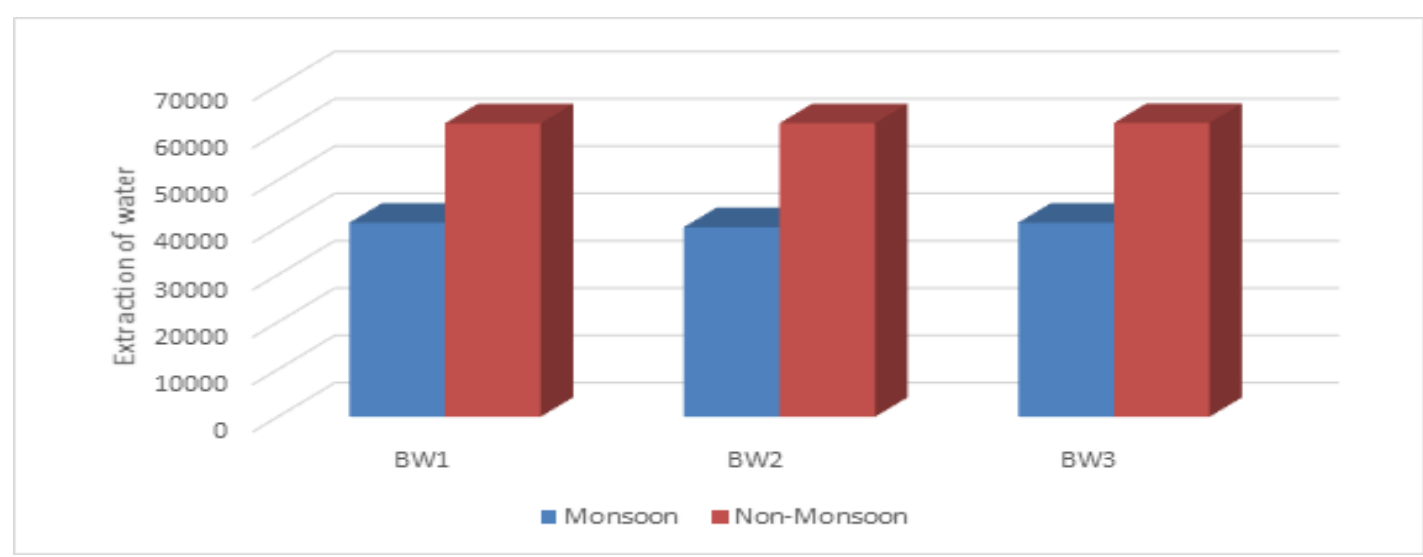

Fig. 4 (b): Extraction rate of water from borewells during monsoon and non-monsoon seasons(ETWFC)

Fig. 4(a). shows the graphical representation of water extraction rate of borewells for 10 weeks in the monitoring network. Fig. 4(b). shows the average rate of extraction of ground water $40 \%$ and $60 \%$ during monsoon and non-monsoon seasons respectively.

5.3. Recharge capability

The recharge capability rate of borewell is measured as follows,

$R_{c}=\frac{\sum W_{d}}{t}$

$W_{d}$ is the flow of water drop inside the borewell and $t$ is the time of water drop in terms of feet per minute.

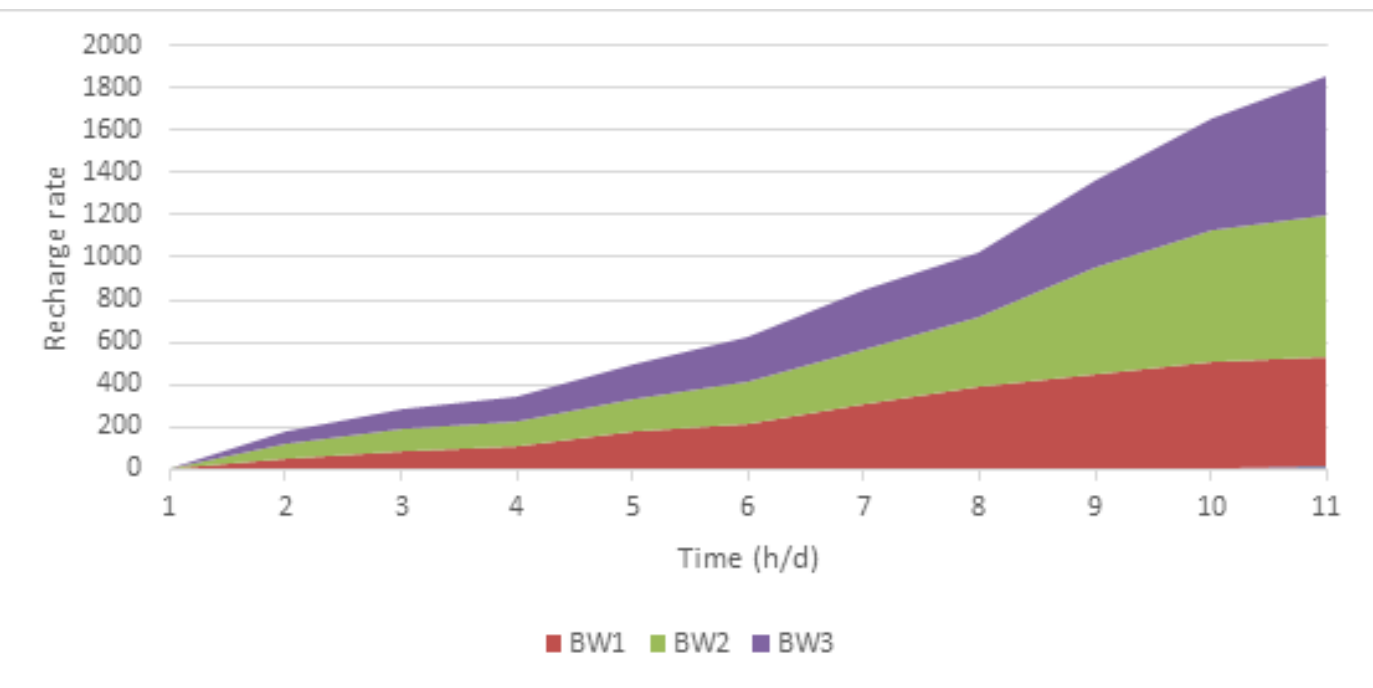

Fig. 5(a): Recharge capability of borewells (ET-WFC) 


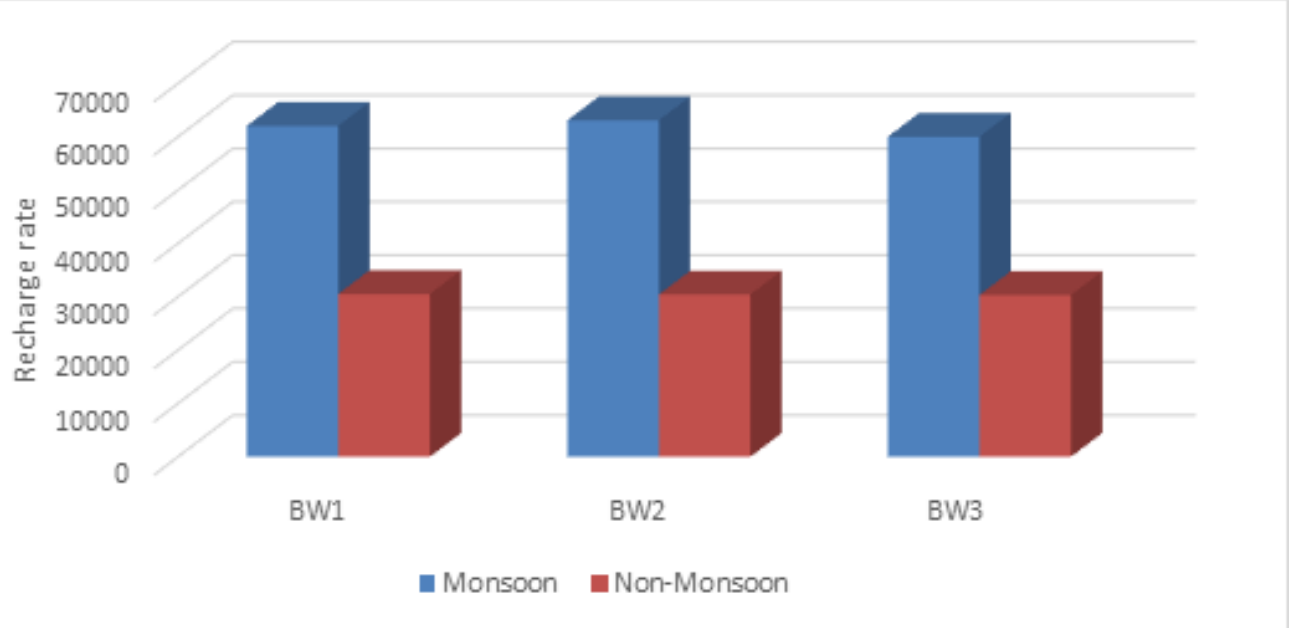

Fig. 5(b): Recharge capability rate of borewells during monsoon and non-monsoon seasons (ET-WFC)

Fig. 5(a). shows the recharge capability of borewells based on time period of the day. Fig. 5(b). represents the average rate of recharge ability of borewells during monsoon and non-monsoon seasons.

5.4. Prediction outcomes

The prediction result of proposed ET-WFC technique is shown in Fig. 6. The graph describes that the future accessibility of groundwater of the borewells, Hence the analytical forecasting result aids the social for effective utilization of groundwater resource.

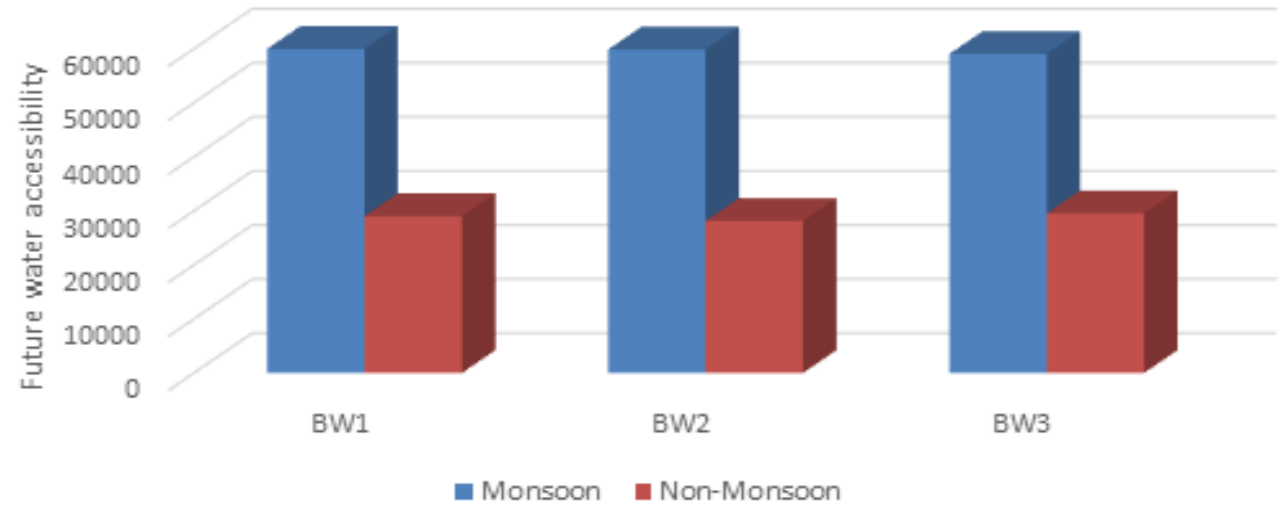

Fig. 6: Prediction result of groundwater accessibility for future using (ET-WFC) technique

\section{Conclusion}

Predicting groundwater level is an essential for farming applications to help farmers manage efficient irrigation systems. Knowing the availability of water resource for cultivation, not only the cultivators able to use less water to cultivate a crop, they are also increase the quality of the crop by enhanced utilization of groundwater during critical plant growth periods. The proposed efficient technique (EF-WFC) for water level forecasting will assist the farmer's aware about the future availability of groundwater resource in order to plan the farming of right crops and prevent them from economic defeat and also increase their stability.

\section{References}

1. Ehteram, M., Afan, H. A., Dianatikhah, M., Ahmed, A. N., Fai, C. M., Hossain, M. S., (2019). Assessing the predictability of an improved ANFIS model for monthly streamflow using lagged climate indices as predictors. Water, 11(6), 1130. 2019.

2. Maroufpoor, S., Fakheri-Fard, A., \& Shiri, J. (2017). Study of the spatial distribution of groundwater quality using soft computing and geostatistical models. ISH Journal of Hydraulic Engineering, 25(2), 232-238.

3. Ghorbani, M. A., Deo, R. C., Karimi, V., Yaseen, Z. M., \& Terzi, O. (2018). Implementation of a hybrid MLPFFA model for water level prediction of Lake Egirdir, Turkey. Stochastic Environmental Research and Risk Assessment, 32(6), 1683-1697.

4. Z. Chen, S. E. Grasby, and K. G. Osadetz, (2002). Predicting average annual groundwater levels from climatic variables: an empirical model. Journal of Hydrology, 260.https://doi.org/10.1016/S0022-1694(01)00606-0 
5. Zhao, G., Pang, B., Xu, Z., Xu, L.,(2019). A Hybrid Machine Learning Framework for Real-Time Water Level Prediction in High Sediment Load Reaches, Journal of Hydrology,https://doi.org/10.1016/j.jhydrol.2019.124422.

6. Pavan Kumar, T., Lala, S. K., Sravani, B., \& Sandeep, A.,(2018). Internet of things survey on crop field smart irrigation automation using IOT. International Journal of Engineering and Technology, 7(2.8 Special Issue 8), 503-506.

7. A.R. Al-Ali, Ahmad Al Nabulsi, Shayok Mukhopadhyay, Mohammad Shihab Awal, Sheehan Fernandes, Khalil Ailabouni, (2019). IoT-solar energy powered smart farm irrigation system. Journal of Electronic Science and Technology,https://doi.org/10.1016/j.jnlest.2020.100017.

8. Amarendra Goap, Deepak Sharma, A.K. Shukla, C. Rama Krishna, (2018). An IoT based smart irrigation management system using Machine learning and open source technologies. Computers and Electronics in Agriculture, 155, 41-49. https://doi.org/10.1016/j.compag.2018.09.040

9. Anne, V. P. K., Durgasai, K. R. V. S. N., Muddineni, R. K., \& Peri, S. G. (2018). Smart irrigation using WSN based on IOT. International Journal of Engineering and Technology, 7, 331-334.

10. NagaGeetha, M., \& Ramesh, N. V. K. (2018). An efficient IoT based smart irrigation system and plant diseases detection: A review. International Journal of Engineering and Technolog, 7, 661-664.

11. Wangtao, Fan., and Gang, Li., (2018). Effect of soil properties on Hydraulic characteristics under subsurface drip irrigation. IOP Conf. Ser.: Earth Environ. Sci., 121052042.

12. Raheman, A., Kameswara Rao, M., Vamsi Reddy, B., \& Ravi Kumar, T. (2018). IOT based self-tracking solar powered smart irrigation system. International Journal of Engineering and Technology, 7, 390-393.

13. Verma, A. K., Bhagavan, K., Akhil, V., \& Singh, A. (2018). Wireless network based smart irrigation system using IOT. International Journal of Engineering and Technology, 7(1.1 Special Issue 1), 342-345.

14. Zhuoheng Chen., Stephen E. Grasby, Kirk G. Osadetz, (2002). Predicting average annul groundwater levels from climatic variables: an empirical model. Journal of Hydrology, 260, 102-117.

15. Deepthi, D., Vasavi, E., Pravallika, K., Swathi, P., \& Rajasekhara Reddy, K. (2017). A study on development of low cost environmental friendly and sustainable irrigation techniques. International Journal of Civil Engineering and Technology, 8(4), 823-829.

16. Narayana, M. V., Dusarlapudi, K., Uday Kiran, K., \& Sakthi Kumar, B. (2017). IoT based real time neonate monitoring system using arduino. Journal of Advanced Research in Dynamical and Control Systems, 9(Special issue 14), 1764-1772.

17. Tao Ren, Xuefeng Liu, Jianwei Niu, Xiaohui Lei, Zhao Zhang, (2020). Real-time water level prediction of cascaded channels based on multilayer perception and recurrent neural network. Journal of Hydrology, 585, 124783, https://doi.org/10.1016/j.jhydrol.2020.124783.

18. Sridevi, S., Bindu Prathyusha, M., \& Krishna Teja, P. V. S. J. (2018). User behavior analysis on agriculture mining system. International Journal of Engineering and Technology(UAE), 7(2), 37-40. doi:10.14419/ijet.v7i2.7.10253.

19. Angel Prathyusha, K., Mahitha, Y., Prasanna Kumar Reddy, N., \& Raja Rajeswari, P. (2018). A survey on prediction of suitable crop selection for agriculture development using data mining classification techniques. International Journal of Engineering and Technology (UAE), 7(3.3 Special Issue 3), 107-109.

20. Tanzeel U. Rehmana, Md. Sultan Mahmudb, Young K. Changb, Jian Jina, Jaemyung Shinb, (2019). Current and future applications of statistical machine learning algorithms for agricultural machine vision systems. Computers and Electronics in Agriculture, 156, 585-605. https://doi.org/10.1016/j.compag.2018.12.006.

21. Narayana, B. V. V. S., Ravi, K. S., \& Ramesh, N. V. K. (2018). A review on advanced crop field monitoring system in agriculture field through top notch sensors. Journal of Advanced Research in Dynamical and Control Systems, 10(6 Special Issue), 1572-1578 